comparisons of NOSACQ results made in different time periods and answered by the trained and untrained personnel, comparisons of accidents rates in various time periods and results of the qualitative data analyses (focus group discussions).

\section{PREVENTING HARM FROM ALCOHOL AND DRUGS AT WORK: NATIONAL STUDY AND DEVELOPMENT OF EDUCATIONAL TOOLS}

${ }^{1}$ Amy Williamson, ${ }^{1}$ Herbert Biggs, ${ }^{2}$ Steve Allsop, ${ }^{3}$ Jo-Anne Abbott. ${ }^{1}$ Queensland University of Technology (QUT), Australia; ${ }^{2}$ Curtin University, Australia; 3 Swinburne University of Technology, Australia

\subsection{6/injuryprev-2016-042156.639}

Background There has long been concern over the impact of alcohol and other drug (AOD) consumption on workplace safety, particularly within the construction industry. Until now there has been little scientific evidence on the relationship between AOD and safety. This research aimed to evaluate AOD within the Australian construction industry and to develop, through engagement with industry, mental health and e-Therapy experts, AOD specific education.

Methods Using the Alcohol Use Disorders Identification Test a national assessment study evaluated the extent of general AOD use in the industry. A survey was distributed to 500 employees across Australia. Semi-structured interviews were also conducted. The researchers collaborated with AOD and e-Therapy experts to develop a web-based AOD program for managers. Researchers then collaborated with an industry-based mental health and suicide prevention organisation. A peer-based AOD education program was developed. It targeted social attitudes to impairment at work and was evaluated through a pilot study with 42 young apprentices.

Results The national assessment study showed that a total of 286 respondents (58\%) scored above the cut-off score for 'risky' alcohol use with 43 respondents (15\%) scoring in the significantly 'at risk' category. Other drug use was also identified as a major issue. The peer-based AOD education program was positively received by young workers. The pilot study showed an increase in both knowledge and awareness of alcohol and drug impairment and intention to seek help.

Conclusions A proportion of the industry is at risk of hazardous alcohol use. Other drugs are also a major issue. Several areas for consideration were identified. Results from the peer-based AOD education program were encouraging and support the need for further evaluation. Web-based programs can enable the provision of AOD education and support (and mental health information more broadly) to those living/working in remote locations.

\section{TACKLING STRESS IN THE WORKPLACE}

Jaana Vastamäki. Ministry of Social Affairs and Health, Finland

\subsection{6/injuryprev-2016-042156.640}

Background Work related stress is a wide spread problem in Europe and also in Finland. Almost one third of the workforce report experiencing work stress and stress related symptoms, such as sleeping disorders and problems concentrating, are common problems among employees. Especially, experienced job insecurity and not having enough time to accomplish their duties properly are the most common problems reported in many surveys.

Description of the problem Even though employers are obligated by the Finnish legislation to take measures to analyse the workload factors and to avoid or reduce the risk, not all employers even recognise the psychosocial workload factors. Furthermore, employers and workplaces in general have too little information about the health risks caused by work stress and about the links between stress and other work related factors, such as sick leaves, workplace accidents and reduced productivity. Results This presentation will describe actions taken in Finland to tackle work stress with the target of prolonging work careers and to reduce sick leaves and early retirement. Actions at all levels will be presented, i.e. in the strategic level, planning and implementation.

Conclusions Tackling work stress requires effective measures both in the policy level and in practical implementation. Successful measures are based in co-operation between governmental institutes, research institutes, trade unions and practitioners.

\section{Epidemiology, Technology - Solutions and Applications for Safety}

\section{Post Tue 2.3}

\section{RISKY DRIVING, UNSAFE VEHICLES AND CAR CRASH INJURY: A POPULATION-BASED CASE-CONTROL STUDY IN FIJI}

${ }^{1}$ Iris Wainiqolo, ${ }^{1}$ Bridget Kool, ${ }^{2}$ Berlin Kafoa, ${ }^{1}$ Josephine Herman, ${ }^{2}$ Eddie McCaig, ${ }^{1}$ Shanthi Ameratunga. ${ }^{1}$ The University of Auckland, New Zealand; ${ }^{2}$ Fiji National University, Fiji

10.1136/injuryprev-2016-042156.641

Background Risky driving and unsafe vehicles are two areas receiving increased global attention as priorities for road traffic injury prevention. However, the attendant risks have not been quantified in low- and middle-income Pacific nations using controlled epidemiological studies.

Methods A population-based case-control study was designed to include all four-wheeled motor vehicles involved in crashes where at least one occupant died or was hospitalised (case vehicles) and a random sample of vehicles driven on roads in Viti Levu, Fiji (control vehicles). The drivers or their proxies were administered structured questionnaires eliciting self-reported data on risky driving and vehicle factors, including crash involvement and traffic convictions in the previous five years.

Results Drivers of 154 case and 752 control vehicles participated in this study. Multivariable models of the main effects of interest found significant excess in the odds of injury-involved motor vehicle crashes (MVCs) with vehicles older than 10 years (OR 1.99; 95\% CI: 1.27-3.12); vehicles with seat belts only in the front seats (OR 2.03; 95\% CI: 1.19-3.46) and speeding up when someone tries to pass (OR 3.40; 95\% CI: 1.51-7.65). The odds of MVC were significantly less if drivers had experienced a traffic conviction or crash in the previous 5 years (OR $0.43 ; 95 \% \mathrm{CI}$ : $0.24-0.78$ and OR 0.45 ; 95\% CI: 0.22, 0.95, respectively).

Conclusions Speeding in some contexts and driving vehicles older than 10 years or without a full complement of seatbelts were associated with a 2-3 fold increase in the odds of serious injury-involved MVCs. In contrast to some other studies, previous traffic convictions and crash involvement appeared 